\title{
UJI DAYA HASIL BEBERAPA VARIETAS TANAMAN GANDUM (Triticum Aestivum L.) PADA DATARAN MEDIUM DI KABUPATEN LOMBOK TIMUR
}

\author{
YIELD OF SEVERAL WHEAT VARIETIES (Triticum Aestivum L.) IN \\ MEDIUM ALTITUDE OF EAST LOMBOK
}

\author{
Lina Andriyanti*, Uyek Maik Yakop, Dwi Ratna Anugrahwati
}

Program Studi Agroekoteknologi, Fakultas Pertanian Universitas Mataram, Mataram, Indonesia
*Email Penulis Korespondensi: andriyanti @ gmail.com

\begin{abstract}
ABSTRAK
Peneitian ini bertujuan untuk mengetahui daya hasil beberapa varietas tanaman gandum (Triticum Aestivum L.) di dataran medium di Kabupaten Lombok Timur. Percobaan dilakukan pada bulan Juni sampai dengan bulan September 2018 di Dusun Trawangan Desa Perian, Kecamatan Montong Gading, Kabupaten Lombok Timur dengan ketinggian tempat \pm 400 mdpl. Rancangan yang digunakan adalah Rancangan Acak Kelompok (RAK) dengan satu faktor yaitu varietas gandum yang terdiri dari 2 varetas Nasional (Nias dan Dewata) dan 5 varietas introduksi (Axe, Gladius, Corel, Scout, Mace) dan masingmasing diulang sebanyak 3 kali sehingga didapat 21 unit perlakuan. Data dianalisis dengan menggunakan Analisis of Variance (ANOVA) pada taraf 5\%. Hasil percobaan menunjukkan bahwa karakter varietas yang ditanam di dataran menengah beragam kecuali bobot berangkasan kering, jumlah spikelet dan jumlah biji yang tidak berbeda dan varietas yang menunjukkan hasil yang cukup baik dengan umur panen yang tidak terlalu lama adalah Nias dan Dewata sebagai varietas Nasional dan Gladius sebagai genotipe Introduksi.
\end{abstract}

Kata Kunci: Uji Daya Hasil, Varietas, Dataran Medium

\begin{abstract}
This study aimed to identify yield of several wheat varieties planted in medium altitude in Lombok Timur. The experiment was conducted from June to September 2018 in Trawangan Hamlet Perian Village, Montong Gading District, East Lombok Regency having altitude of $500 \mathrm{~m}$ above sea level. The experiment design used was a Randomized Complete Block Design (RCBD) with one factor treatment namely wheat varieties consisting of 2 national varieties (Nias and Dewata) and 5 introduced varieties (Axe, Correl, Gladius, Mace and Scout). Each treatment was repeated three times so that there were total of 21 treatment units. Data were analyzed using Analysis of Variance (ANOVA) at 5\% level. The results of the experiment showed that several varieties grown at medium altitude diversed in agronomic characters unless dry weight matter, spicelete numbers and the number of seeds per plant. of wheat plants tested. The varieties showing promising in yield with lower periode of harvest were Nias and Dewata as National varieties and Gladius as an introduced genotype.
\end{abstract}

Keywords: Growth Phase, Variety, Medium Plain

\section{PENDAHULUAN}

Gandum (Triticum aestivum L.) merupakan salah satu tanaman serealia dari famili Gramineae (Poaceae). Komoditas ini merupakan bahan makanan penting di dunia sebagai sumber karbohidrat dan protein. Gandum merupakan pangan pokok bagi sebagian besar penduduk dunia dan merupakan bahan baku tepung terigu yang banyak digunakan untuk pembuatan berbagai produk makanan seperti roti, kue, mie, kue biskuit dan makanan ringan lainnya (Wiyono, 1980).

Indonesia tercatat sebagai negara pengimpor gandum terbesar kedua di dunia. Berdasarkan laporan United State Departement of Agriculure (USDA) Mei 2012, impor gandum Indonesia diprediksi menembus 7,1 juta ton, dibandingkan dengan tahun sebelumnya yang hanya 6,7 juta ton. Kebutuhan terigu di Indonesia pada tahun 2004 mencapai 5,4 juta metrik ton. Kebutuhan terigu yang begitu besar dipasok dengan impor 
gandum sebesar 7,4 juta metrik ton yang menjadikan Indonesia sebagai importir gandum terbesar ke-4 dunia setelah Mesir, Cina dan Brazil. Oleh karena itu, produksi gandum lokal di tempat yang sesuai agroekosistem harus diupayakan agar dapat mengurangi impor gandum dari negara lain.

Manfaat gandum sebagai sumber bahan pangan sangat beragam terutama dalam memenuhi diversifikasi pangan seperti makanan ringan roti,mie,biskuit,puding dan kue. Kebutuhan tepung terigu di Indonesia terus meningkat karena adanya perubahan pola makan masyarakat,ditambah lagi dengan maraknya makanan yang berasal dari luar seperti pizza, donut, dan spagheti (Suhendra, 2009).

\section{METODE PENELITIAN}

Percobaan dilakukan pada bulan Juni sampai dengan bulan September 2018 di Dusun Trawangan Desa Perian, Kecamatan Montong Gading, Kabupaten Lombok Timur dengan ketinggian tempat \pm 400 mdpl.Varietas gandum yang digunakan dalam percobaan ini adalah dua varietas Nasional (Nias dan Dewata) dan lima varietas introduksi dari Australia (Axe, Gladius, Corell, Scout dan Mace). Rancangan yang digunakan adalah Rancangan Acak Kelompok (RAK) degan tujuh varietas dan setiap varietas diulang tiga kali sehingga didapat 21 unit percobaan.

Benih yang dipilih adalah yang bernas, tidak keriput, tidak cacat dan yang relatif besarnya sama kemudian benih tiap varietas dihitung sebanyak 150 biji dan dimasukkan ke dalam plastik yang sudah disiapkan untuk kebutuhan 1 larikan/baris sepanjang $3 \mathrm{~m}$.

Pengolahan tanah pada tanaman gandum dilakukan dengan cara dibajak.Hal ini bertujuan untuk menggemburkan tanah dan membasmi gulma.Setelah pengolahan tanah dilakukan maka dibuatlah petak dengan ukuran masing-masing petak 1 x 3 meter sebanyak 21 petak dengan jarak tanam $20 \times 30 \mathrm{~cm}$.Penanaman dilakukan dengan cara membuat larikan/baris setiap petak yang terdiri dari 4 larikan sepanjang 3 meter dan di tugal, pada setiap barisan/larikan terdapat 150 benih tanaman gandum.Untuk mencegah hama maka selanjutnya ditaburi insektisida Furadan secukupnya disekitar benih yang sudah disebar.

Pupuk diberikan pada saat penanaman dengan cara dibuatkan larikan/baris sedalam 2 cm pada sela-sela baris tanaman.Pupuk yang diberikan yaitu pupuk NPK dan Urea dengan dosis pupuk masing-masing $300 \mathrm{~kg} / \mathrm{ha}$.Pupuk NPK diberikan seluruhnya pada saat penanaman, sedangkan pupuk Urea diberikan 3 kali yaitu dengan 1/3 Urea setiap kali pemupukan yaitu saat tanam dan ketika tanaman berumur 3 minggu dan 6 minggu setelah tanam.

Pemeliharaan tanaman meliputi pengairan dan pengendalian gulma. Pengairan dilakukan 2 minggu sekali sampai 2 minggu menjelang panen. Sedangkan untuk pengendalian gulma dilakukan secara manual selama fase pertumbuhan tanaman dan perkembangan tanaman dengan cara disiangi dengan sabit, yaitu 2 kali pada umur 2 minggu dan 4 minggu setelah tanam. Panen dilakukan ketika $80 \%$ populasi tanaman gandum dalam setiap perlakuan sudah menunjukkan kriteria panen yaitu menguning, mengering dan biji sudah mulai mengeras.Panen dilakukan dengan cara menyabit jerami gandum. Pada percobaan ini parameter pengamatan terdiri dari : tinggi tanaman, bobot berangkasan kering $/ \mathrm{m}^{2}$, jumlah batang $/ \mathrm{m}^{2}$, jumlah malai $/ \mathrm{m}^{2} /$, jumlah spikelet $/ \mathrm{m}^{2} /$, jumlah biji $/ \mathrm{m}^{2} /$, bobot 1000 butir, bobot biji $/ \mathrm{m}^{2}$. 


\section{HASIL DAN PEMBAHASAN}

Hasil analisis ragam (ANOVA) menunjukkan bahwa terdapat keragaman sifat pada pertumbuhan. Beberapa sifat yang menunjukkan perbedaan yang nyata antara lain tinggi tanaman, jumlah batang, umur berbunga, umur panen, jumlah malai $/ \mathrm{m}^{2}$, bobot $1000 \mathrm{biji}$ dan bobot biji $/ \mathrm{m}^{2}$, sedangkan variabel yang tidak menunjukkan adanya perbedaan yang nyata antara lain Bobot berangkasan kering $/ \mathrm{m}^{2}$, jumlah spiklet $/ \mathrm{m}^{2}$ dan jumlah $\mathrm{biji} / \mathrm{m}^{2}$. Hasil Uji Lanjut (BNJ) untuk beberapa variabel yaitu Tinggi tanaman, Jumlah batang, Umur berbunga dan umur panen di sajikan pada Tabel 1. Adapun variabel Jumlah malai $/ \mathrm{m}^{2}$, Bobot 1000 biji, dan Bobot biji $/ \mathrm{m}^{2}$ di sajikan pada Tabel 2.

Tabel 1. Rata-rata Variabel Pengamatan untuk Tinggi tanaman, Jumlah batang, Umur berbunga dan Umur panen pada Berbagai Varietas yang diuji

\begin{tabular}{|c|c|c|c|c|}
\hline Perlakuan & $\begin{array}{c}\text { Tinggi } \\
\text { tanaman }(\mathrm{cm})\end{array}$ & Jumlah batang/m² & $\begin{array}{c}\text { Umur berbunga } \\
\text { (HST) }\end{array}$ & $\begin{array}{c}\text { Umur panen } \\
(\text { HST })\end{array}$ \\
\hline Nias & $91,63 \mathrm{ab}$ & $420,00 \mathrm{bc}$ & $48,67 \mathrm{de}$ & $86,00 \mathrm{de}$ \\
\hline Dewata & $86,67 \mathrm{~b}$ & $345,83 \mathrm{c}$ & $54,33 \mathrm{~cd}$ & $91,67 \mathrm{~cd}$ \\
\hline Axe & $68,77 \mathrm{c}$ & $571,67 \mathrm{a}$ & $48,00 \mathrm{e}$ & $84,00 \mathrm{e}$ \\
\hline Gladius & $100,93 \mathrm{a}$ & $486,67 \mathrm{abc}$ & $54,67 \mathrm{~cd}$ & $95,00 \mathrm{bc}$ \\
\hline Corell & $68,90 \mathrm{c}$ & $530,00 \mathrm{ab}$ & $59,33 b c$ & $100,67 \mathrm{ab}$ \\
\hline Scout & $69,33 \mathrm{c}$ & $435,83 \mathrm{abc}$ & $83,67 \mathrm{a}$ & $106,00 \mathrm{a}$ \\
\hline Mace & $68,77 \mathrm{c}$ & $539,17 \mathrm{ab}$ & $62,00 \mathrm{~b}$ & $102,00 \mathrm{ab}$ \\
\hline Rata-rata & 79,28 & 475,5 & 58,66 & 95,04 \\
\hline BNJ 5\% & 12,6 & 147,98 & 6,18 & 7,65 \\
\hline
\end{tabular}

keterangan: Angka yang diikuti oleh huruf yang sama pada kolom yang sama menunjukkan tidak berbeda nyata pada uji lanjut BNJ taraf 5\%.

Sumber: Data Primer diolah (2020)

Tabel 2. Rata-rata Variabel Pengamatan Bobot berangkasan kering/ $\mathrm{m}^{2}$, Jumlah malai $/ \mathrm{m}^{2}$, Jumlah spikelet $/ \mathrm{m}^{2}$, Jumlah biji $/ \mathrm{m}^{2}$, Bobot1000 biji (g), dan Bobot biji $/ \mathrm{m}$.

\begin{tabular}{lllllll}
\hline Perlakuan & $\begin{array}{c}\text { Bobot } \\
\text { berangkasan } \\
\text { kering }(\mathrm{g})\end{array}$ & $\begin{array}{c}\text { Jumlah } \\
\text { malai/m² }\end{array}$ & $\begin{array}{c}\text { Jumlah } \\
\text { spikelet } \\
/ \mathrm{m}^{2}\end{array}$ & $\begin{array}{c}\text { Jumlah } \\
\text { biji/m² }\end{array}$ & $\begin{array}{c}\text { Bobot } \\
1000 \\
\text { biji }(\mathrm{g})\end{array}$ & $\begin{array}{c}\text { Bobot biji } \\
(\mathrm{g})\end{array}$ \\
\hline Nias & 756,08 & $405,00 \mathrm{bc}$ & 5078,33 & 6680,02 & $31,55 \mathrm{ab}$ & $317,08 \mathrm{a}$ \\
Dewata & 745,75 & $335,83 \mathrm{c}$ & 4779,17 & 4828,43 & $33,17 \mathrm{ab}$ & $276,08 \mathrm{ab}$ \\
Axe & 481,50 & $563,33 \mathrm{ab}$ & 1687,17 & 2381,91 & $34,34 \mathrm{ab}$ & $145,25 \mathrm{c}$ \\
Gladius & 648,92 & $478,33 \mathrm{ab}$ & 1462,44 & 6585,83 & $35,92 \mathrm{a}$ & $234,08 \mathrm{abc}$ \\
Corell & 688,25 & $503,33 \mathrm{ab}$ & 1697,92 & 2753,54 & $36,32 \mathrm{a}$ & $168,08 \mathrm{bc}$ \\
Scout & 713,33 & $422,50 \mathrm{bc}$ & 5162,50 & 6216,48 & $27,63 \mathrm{c}$ & $259,75 \mathrm{abc}$ \\
Mace & 757,58 & $495,00 \mathrm{ab}$ & 3536,84 & 3133,79 & $23,03 \mathrm{c}$ & $262,83 \mathrm{abc}$ \\
\hline Rata-rata & 683,63 & 457,61 & 3343,48 & 4654,29 & 31,708 & 237,16 \\
\hline BNJ 5\% & 291,64 & 134,90 & & & 7,72 & 119,59 \\
\hline Ken
\end{tabular}

Keterangan: Angka yang diikuti oleh huruf yang sama pada kolom yang sama menunjukkan tidak berbeda nyata pada uji lanjut BNJ taraf 5\%.

Sumber: Data Primer diolah (2020)

Tinggi tanaman, dari semua varietas yang diuji berkisar antara 68,77-100,93 cm. Tanaman tertinggi di dapatkan pada varietas Gladius dengan tinggi 100,93 cm walaupn 
tidak berbeda nyata dengan Nias $(91,63 \mathrm{~cm})$, sedangkan Varietas yang menunjukkan tinggi tanaman paling rendah yaitu Mace dengan tinggi $(68,77 \mathrm{~cm})$, Scout $(69,33 \mathrm{~cm})$, Corell $(68,9 \mathrm{~cm})$, dan Axe $(68,77 \mathrm{~cm})$. Jumlah batang $/ \mathrm{m}^{2}$ berkisar antara 345,83-571,67 batang. Tanaman yang memiliki jumlah batang paling banyak yaitu Axe dengan 571,67 batang meskipun tidak berbeda nyata dengan varietas Gladius, Corell, Scout dan Mace. Adapun tanaman yang memiliki jumlah batang paling sedikit yaitu Dewata dengan 345,83 batang, meskipun tidak berbeda nyata dengan Nias (420,00 btg), Gladius (486,67 btg), dan Scout (435,83 btg). Dalam penelitian Misran (2014) dan Prayogi (2017), menyatakan intensitas penyinaran dan ruang tumbuh untuk tanaman sehingga pertumbuhan menjadi tidak optimal. Adanya perbedaan tinggi tanaman pada suatu varietas disebabkan oleh pengaruh lingkungan (Wati, 2015).

Umur berbunga berkisar antara 48,00-83,67 hari setelah tanam (hst). Tanaman yang berbunga paling awal terjadi pada Axe (48,00 hst) dan Nias (48,67 hst). Sedangkan tanaman yang berbunga paling lama adalah Scout (83,67 hst). Varietas Corell $(59,33$ hst) termasuk berbunga medium, tidak berbeda nyata dengan Gladius (54,67 hst) dan Dewata (54,33 hst). Rawson et al. (1996) mengungkapkan bahwa suhu udara yang terlalu tinggi mengakibatkan meningkatnya aktivitas respirasi dan pemasakan bulir yang terlalu cepat.

Umur panen paling lama terjadi pada varietas Scout yaitu 106,00 hst meskipun tidak berbeda nyata dengan Corell (100,67 hst). Adapun varietas yang paling awal umur panen adalah varietas Axe yaitu 84,00 hst, meskipun tidak berbeda dengan varietas Nias (86,00 hst).

Jumlah malai $/ \mathrm{m}^{2}$ yang dihasilkan pada perlakuan tersebut berkisar antara 335,83$563,33 \mathrm{malai} / \mathrm{m}^{2}$. Tanaman yang menghasilkan jumlah malai $/ \mathrm{m}^{2}$ banyak adalah Axe $(563,33)$, Gladius yaitu478,33, Corel yaitu 503,33, dan Mace sebanyak 495,00. Sedangkan jumlah yang lebih rendah adalah varietas Dewata, Nias dan Scout, masingmasing 335,83, 405,00 dan 422,50malai $/ \mathrm{m}^{2}$. Berat berankasan kering (g) yang dihasilkan berkisar antara 481,50-757,58bbk g, tanaman yang menghasilkan jumlah berangkasan kering paling banyak terdapat pada Mace $(757,58 \mathrm{bbk}$ g), sedangkan tanamn yng menghasilkan berat berangkasan kering paling sedikit terdapat pada Axe (481,50bbk g). Berat berangkasan kering pada Mace $(757,58 \mathrm{bbk}$ g) tiak berbeda nyata dengan Axe (481,50bbk g), nias $(756,08 \mathrm{bbk}$ g), dewata $(745,75 \mathrm{bbk} \mathrm{g})$, Scout (713,33bbk g), corell $(688,25 \mathrm{bbk}$ g), Gladius $(648,92 \mathrm{bbk} \mathrm{g})$. Intensitas radiasi matahari mempengaruhi jumlah karbohidrat yang dihasilkan melalui proses fotosintesis. Sehingga jumlah malai per satuan luas, jumlah bulir isi per malai dan bobot rata-rata gabah dipengaruhi oleh penerimaan radiasi (Riyadi, 2004).

Jumlah malai $/ \mathrm{m}^{2}$ yang dihasilkan pada perlakuan tersebut berkisar antara 335,83563,33 malai $/ \mathrm{m}^{2}$. Tanaman yang menghasilkan jumlah malai $/ \mathrm{m}^{2}$ paling banyak terdapat pada Axe $\left(563,33\right.$ malai $\left./ \mathrm{m}^{2}\right)$ dan tanaman yang menghasilkan jumlah malai $/ \mathrm{m}^{2}$ paling sedikit terdapat pada Dewata $\left(335,83 \mathrm{malai} / \mathrm{m}^{2}\right)$. Jumlah malai $/ \mathrm{m}^{2}$ pad Axe $\left(563,33 \mathrm{malai} / \mathrm{m}^{2}\right)$ tidak berbeda nyata dengan Dewata $\left(335,83 \mathrm{malai} / \mathrm{m}^{2}\right)$. Penggunaan jumlah bibit yang terlalu banyak maka produksi akan menjadi tidak optimal (Aji, 2016). Jumlah anakan termasuk variabel yang penting untuk diketahui karena berpengaruh terhadap hasil panen (Suriani et al., 2014). Budiarti et al., 2005, menyatakan bahwa jumlah anakan pertanaman berpengaruh langsung terhadap hasil per tanaman sehingga dapat dijadikan kriteria seleksi untuk mendapatkan genotipe gandum yang berpotensi tinggi. Semakin tinggi jumlah anakan produktif, maka biji yang dihasilkan akan semakin meningkat. 
Jumlah spikelet $/ \mathrm{m}^{2}$ yang dihasilkan berkisar antara $1462,44-5162,50$ spikelet $/ \mathrm{m}^{2}$, tanaman yang menghasilkan jumlak spikelet erbanyak terdapat pada Scout(5162,50 spikelet $/ \mathrm{m}^{2}$ ) sedangkan tanaman yang menghasilkan jumlah spikelet paling sedikit terdapat pada Gladius $\left(1462,44\right.$ spikelet $\left./ \mathrm{m}^{2}\right)$. Jumlah spikelet $/ \mathrm{m}^{2}$ yang dihasilkan bervariasi yaitu, Scout $\left(5162,50\right.$ spikelet $\left./ \mathrm{m}^{2}\right)$, Nias $\left(5078,33\right.$ spikelet $\left./ \mathrm{m}^{2}\right)$, Dewata $\left(4779,17\right.$ spikelet $\left./ \mathrm{m}^{2}\right)$, Mace $\left(3536,84\right.$ spikelet $\left./ \mathrm{m}^{2}\right)$, Corel $\left(1697,92 \mathrm{spikelet} / \mathrm{m}^{2}\right)$, Axe $\left(1687,17\right.$ spikelet $\left./ \mathrm{m}^{2}\right)$, Gladius $\left(1462,44\right.$ spikelet $\left./ \mathrm{m}^{2}\right)$, Jumlah $\mathrm{biji} / \mathrm{m}^{2}$ yang dihasilakan pada perlakuan tersebut berkisar antara 2381,91-6680,02 biji $/ \mathrm{m}^{2}$. Tanaman yang memiliki jumlah biji $/ \mathrm{m}^{2}$ yang paling banyak yaitu Nias $\left(668,02 \mathrm{biji} / \mathrm{m}^{2}\right)$ dan tanaman yang memiliki jumah biji $/ \mathrm{m}^{2}$ paling sedikit yaitu Axe $\left(2381,91 \mathrm{biji} / \mathrm{m}^{2}\right)$. Jumlah $\mathrm{biji} / \mathrm{m}^{2}$ pada Nias $\left(6680,02 \mathrm{biji} / \mathrm{m}^{2}\right)$, Dewata $\left(4828,43 \mathrm{biji} / \mathrm{m}^{2}\right)$, Mace $\left(3133,79 \mathrm{biji} / \mathrm{m}^{2}\right)$, Corel $\left(2753,54 \mathrm{biji} / \mathrm{m}^{2}\right)$. Handoko (2007) menyatakan bahwa, proses pengisian biji dari hasil fotosintesis selama fase generatif yang ditentukan oleh faktor radiasi matahari sebagai energi fotosintesis.

Bobot 1000 biji yang dihasilkan pada perlakuan tersebut berkisar antara 23,03-36,32 $\mathrm{g}$ dan tanaman yang memiliki bobot 1000 biji yang paling tinggi yaitu Corell dengan $(36,32 \mathrm{~g})$ akan tetapi tidak berbeda nyata dengan varietas Gladius (35,92 g), Axe $(34,34)$, Dewata $(33,17 \mathrm{~g})$, Nias $(31,55 \mathrm{~g})$. Adapun tanaman yang memiliki bobot 1000 biji termasuk lebih rendah adalah Mace dengan $(23,03 \mathrm{~g}$ ) yang tidak berbeda dengan Scout $(27,63 \mathrm{~g})$ (Tabel 3).

Bobot biji $/ \mathrm{m}^{2}$ yang dihasilkan pada perlakuan tersebut berkisar antara 145,25-317,08 $\mathrm{g} / \mathrm{m}^{2}$, tanaman yang menghasilkan bobot biji tertinggi terdapat pada Nias $\left(317,08 \mathrm{~g} / \mathrm{m}^{2}\right)$ dan tidak berbeda dengan Dewata $\left(276,08 \mathrm{~g} / \mathrm{m}^{2}\right)$, Mace $\left(262,83 \mathrm{~g} / \mathrm{m}^{2}\right)$, Scout $(259,75$ $\left.\mathrm{g} / \mathrm{m}^{2}\right)$, dan Gladius $\left(234,08 \mathrm{~g} / \mathrm{m}^{2}\right)$. Tanaman yang memiliki hasil paling rendah terjadi pada Axe $(145,25)$.

Perbedaan respon varietas terhadap sifat pertumbuhan dan hasil juga terjadi di dataran rendah maupun di dataran tinggi. Hasil Penelitian Wahyu et al (2013) yang ditanam di dataran rendah di daerah Bogor pada ketinggian $300 \mathrm{~m}$ dpl telah dilaporkan. 12 genotipe yang berasal dari introduksi dari India dan Turki dan 2 pembanding yaitu varietas nasional (Dewata dan Selayar) telah menunjukkan hasil yang serupa, yakni varietas menunjukkan beragam terhadap keseluruhan karakter yang amati kecuali karakter jumlah anakan produktif yang tidak berbeda nyata. Keragaman karakter varietas juga terjadi pada daerah dataran tinggi. Varietas/galur Gandum sebanyak 12 jenis yang di tanam di dataran tinggi di tanah tinggi Karo $( \pm 1390 \mathrm{~m})$ menunjukkan perbedaan yang nyata terhadap semua parameter pertumbuhan dan hasil, termasuk didalamnya varietas nasional yaitu Dewata dan Selayar (Wirawan, et al., 2013). Subagyo (2001) dalam Wahyu et al (2013) mengungkapkan bahwa di daerah tropis, ketinggian tempat tanam memberi pengaruh positif terhadap tinggi tanaman dan panjang malai. Semakin tinggi tempat tanam, semakin meningkat pula tinggi tanaman dan panjang malai yang terbentuk.

Dilihat secara umum dua varietas dalam penelitian ini menunjukkan adaptasinya yang cukup baik apabila dilihat dari hasil dan umur panen yang tidak terlalu lama, yaitu Nias dan Dewata. Kedua varietas ini tidak menunjukkan perbedaan yang nyata baik dari hasil yang cukup tinggi, masing-masing berbobot $317.08 \mathrm{biji} / \mathrm{m}^{2}$ dan $276.08 \mathrm{biji} / \mathrm{m}^{2}$ maupun umur panen yang tidak dalam, yaitu 86 dan 91.67 hst. Dari beberapa hasil penelitian di berbagai ketinggian, Dewata termasuk varietas yang adaptif dan relatif stabil serta direkomendasikan di dataran rendah (Wahyu et al., 2013), di dataran menengah (Widowati et al., 2016), dan di dataran tinggi (Wirawan, et al., 2013). Varietas Introduksi yang juga menunjukkan adaptasinya yang cukup bagus di dataran 
menengah adalah Gladius. Varietas ini dapat berproduksi cukup menjanjikan tidak berbeda nyata dengan Nias maupun Dewata yaitu seberat $248.08 \mathrm{biji} / \mathrm{m}^{2}$, dan umur panen yang tidak terlalu lama, yaitu 95 hst, tidak berbeda nyata dengan Dewata meskipun lebih lama dari Nias. Varietas introduksi ini dapat direkomendasikan untuk ditanam di dataran menengah terkait dengan produksi dan umur tanaman yang tidak terlalu lama.

\section{KESIMPULAN DAN SARAN}

\section{Kesimpulan}

Berdasarkan hasil penelitian dan pembahasan yang telah dilakukan dapat disimpulkan bahwa Berbagai varietas yang ditanam di dataran menengah menunjukkan karakter yang beragam kecuali bobot berangkasan kering, jumlah spikelet dan jumlah biji yang tidak berbeda secara nyata. Varietas yang yang menunjukkan hasil cukup baik dengan umur panen yang tidak terlalu lama adalah varietas Nias dan Dewata sebagai varietas Nasional dan Gladius sebagai genotipe Introduksi.

\section{Saran}

Dari hasil percobaan ini disarankan perlu adanya penelitian lebih lanjut terhadap hasil dan pertumbuhan tanaman gandum pada dataran yang lebih rendah terutama untuk genotipe Gladius.

\section{DAFTAR PUSTAKA}

Aji, W. (2016). Keunggulan dan Kelemahan Sistem Tanam Padi Tehnik Hazton. https://kabartani.com/keunggulan-dan-kelemahan-sistem-tanam-padi-tehnikhazton.html. Diakses tanggal 11 April 2020.

Budiarti, S.G. (2005). Karakterisasi Beberapa Sifat Kuantitatif Plasma Nutfah Gandum. Buletin Plasma Nutfah. 2(11), 49-54.

Handoko. (2007). Penelitian Pengembangan Gandum di Indonesia. Seameo Biotrop: Bogor.

Misran, M. (2017). Efisiensi Penggunaan Jumlah Bibit Terhadap Pertumbuhan dan Produksi Padi Sawah. Jurnal Penelitian Pertanian Terapan, 14(1). https://doi.org/10.25181/jppt.v14i1.140

Mutyarini, Kuswardani \& Sembiring, Jaka 2006, 'Arsitektur Sistem Informasi Untuk Institusi Perguruan Tinggi di Indonesia', Proceedings Konferensi Nasional Teknologi Informasi dan Komunikasi untuk Indonesia, Laboratorium Sinyal dan Sistem Dept. Teknik Elektro ITB, Bandung, 6.

Prayogi, K. (2017). Uji Daya Hasil Beberapa Varietas Padi (Oryza sativa L.) Dengan Metode Hazton [Skripsi]. Medan: Universitas Muhammadiyah Sumatera Utara.

Rawson, H. M., Zajac, M., \& Noppakoonwong, R. (1996). Effects of temperature, light and humidity during the phase encompassing pollen meiosis on floret fertility in wheat. Sterility in Wheat in Subtropical Asia: Extent, Causes and Solutions, 7884. https://agris.fao.org/agris-search/search.do?recordID=US201301525225

Rawson, H.M., Zajac, M., \& Napkoonwang, R. N. (1996). Effect of temperature light and humidity during the phase encompassing pollen meiosis on floret fertility in wheat. Sterility Wheat in Subtropical Asia: Extent Causes and Solution ACIAR Proceeding. In H.M. Rawson, K.D. Subedi (Eds.) 78-84... Sydney. 
Riyadi, A. S. (2004). Uji daya hasil beberapa galur gandum (Triticum spp) di dataran sedang di kecamatan Ampel kabupaten Boyolali [Skripsi]. Surakarta: Universitas Sebelas Maret.

Suriani, Ambo A, \& M. Farid. (2014). Uji Adaptasi Beberapa Genotipe Gandum (Triticum Aestivum L.) Pada Dataran Rendah. J. Sains \& Teknologi. 14(3), 269276.

Wahyu, Y., Samosir, A. P. \& Budiarti, S. G. (2013). Adaptabilitas Genotipe Gandum Introduksi di Dataran Rendah. Bul. Agrohorti, 1(1), 1-6.

Wati, R. (2015). Respon Pertumbuhan dan Produksi Beberapa Varietas Padi Unggul Lokal dan Unggul Baru Terhadap Variasi Intensitas Penyinaran [Skripsi]. Medan: Universitas Muhammadiyah Sumatera Utara.

Widowati, S., Khumaida, N., Ardi, S. W. \& Trikoesoemaningtyas. (2016). Karakterisasi Morfologi dan Sifat Kuantitatif Gandum (Triticum aestivum L.) di Dataran Menengah. J. Agron. Indonesia, 44(2), 162-169.

Wirawan, D., Rosmayati, \& Putri, L. A. P. (2013). Uji Potensi Produksi Beberapa Galur/Varietas Gandum (Triticum aestivum L.) di Dataran Tinggi Karo. Jurnal Online Agroekoteknologi, 1(2). 